\title{
1 PROSPECTA
}

\section{Conocimientos de gestión contable y financiera de los dignatarios de las juntas de acción comunal de Sogamoso}

Knowledge of accounting and financial management of the dignitaries of the boards of action communal of Sogamoso

Aymer Román Barrera Novoa*

* Administrador Industrial, Especialista en Gerencia Financiera, Magíster en Administración de Empresas. Docente ocasional tiempo completo de la Universidad Nacional abierta y a Distancia UNAD. Integrante del Grupo Sol de Iraka. Correo electrónico: aymer.barrera@unad.edu.co. Número ORCID: 0000-0003-2365-2135 


\section{Introducción}

Las Juntas de Acción Comunal (en adelante JAC) son las encargadas de representar a las poblaciones ante el Gobierno y de buscar el bienestar ciudadano identificando las principales necesidades del sector. Las JAC se crearon en 1953 para tener ese contacto necesario con las comunidades. En ese tiempo, Colombia vivió el periodo de la violencia, lo que generó el desplazamiento de muchas personas hacia las ciudades, en busca de mejores oportunidades. Esto trajo consigo la necesidad de organizar a la población, en cuyo caso las JAC pretendían no solo organizar a las personas sino buscar beneficios para los ciudadanos.

Por sugerencia de Asocomunal, nace la idea de identificar la situación actual del manejo contable que realizan las JAC. Este estudio se realiza en un término de 18 meses, iniciando con la identificación de la necesidad de capacitar a los comunales sogamoseños, después del desarrollo de un diagnóstico situacional realizado a 82 juntas. Como segundo objetivo, el proyecto plantea el diseño de una cartilla que plasme un modelo de gestión contable y financiera para que sea utilizada como guía por estos organismos comunales. Aunque la finalidad de las JAC no es manejar dinero, muchas de las que hoy existen tienen recursos propios, ya sea por arriendo del salón social, locales, alquiler de escenarios deportivos, proyectos productivos y hasta donaciones. Lo anterior para poder solventar el mantenimiento de estas instalaciones (polideportivos, salones comunales, parques infantiles, etc.); de ahí se genera la necesidad de transferir conocimiento, por parte de la UNAD, a los comunales sobre manejo contable y financiero.

En estudios anteriores realizados por entes de control y vigilancia, la Secretaria de Gobierno de Sogamoso identificó la necesidad de capacitar a las JAC en el manejo contable y financiero, para que los directivos comunales puedan manejar e invertir los recursos obtenidos por diferentes rubros con rectitud y equidad, al ejecutar todas aquellas obras que redunden en beneficio de la comunidad. La Secretaria también resaltó la necesidad de sensibilizar a los miembros de las JAC para que rindan informes de forma periódica a la comunidad y a los entes de control y vigilancia. El buen manejo de estos recursos 
traerá progreso para las localidades, generando emprendimiento, liderazgo y participación comunitaria de la mano con los diferentes entes territoriales, tales como las alcaldías municipales.

\section{Planteamiento del problema}

En la actualidad, ninguna de las 108 juntas afiliadas a Asocomunal está manejando de forma adecuada los dineros que perciben por diferentes conceptos. Este panorama se debe a la falta de mecanismos y herramientas que ayuden a controlar el manejo de los recursos de la comunidad, ya que el único instrumento contable que se utiliza es el libro de caja. En muy pocos casos se manejan estados financieros. De esta forma, el presidente de la JAC ejecuta los pocos recursos que percibe sin planeación, control del gasto o soportes contables; es decir, sin ningún parámetro o modelo de procesos o procedimientos de manejo de recursos; de acuerdo con el diagnóstico realizado el 61\% de los dignatarios no conoce el manejo de los libros comunales (Secretaria de Gobierno del municipio de Sogamoso). Es de anotar que las entidades territoriales realizan, ocasionalmente, capacitaciones pero sin dejar un parámetro o guía que le permita a las JAC mantener estas prácticas contables, únicamente dejan lo que se menciona en la ley 743. Para hacer frente a esta problemática se propone crear un instrumento guía que siempre esté disponible para los integrantes de las JAC, sin importar el cambio de dignatarios, en especial porque los que inician una junta directiva no siempre son los que finalizan el periodo para el cual fueron elegidos.

\section{Justificación}

Esta investigación se debe realizar porque permite fortalecer la imagen institucional de la UNAD ante las diferentes comunidades existentes en el municipio de Sogamoso, dentro de las cuales están las 108 JAC. Al mismo tiempo, este análisis constituye un aporte a la sociedad, mediante el diseño de lineamientos con los cuales las comunidades podrán tener herramientas financieras 
para controlar los ingresos percibidos por diferentes rubros: arrendamientos, préstamos de instalaciones, actividades comunitarias y donaciones, entre otros; también para controlar sus egresos de forma transparente. De acuerdo con la información suministrada por la Secretaria de Gobierno Municipal de Sogamoso, un $70 \%$ de las JAC no manejan de forma adecuada los libros contables, bien sea por desconocimiento de la ley 743 o por falta de capacitación.

\section{Marco teórico}

La Constitución Política de Colombia, en lo referente a los principios fundamentales, dice en el artículo 2 lo siguiente:

Constitución Política de Colombia. (1991). Titulo 1. De los principios fundamentales. Artículo 2. "Son fines esenciales del Estado: servir a la comunidad, promover la prosperidad general y garantizar la efectividad de los principios, derechos y deberes consagrados en la Constitución; facilitar la participación de todos en las decisiones que los afectan y en la vida económica, política, administrativa y cultural de la Nación; defender la independencia nacional, mantener la integridad territorial y asegurar la convivencia pacífica y la vigencia de un orden justo".

En ese sentido, el marco conceptual de la contabilidad pública en Colombia tiene los siguientes objetivos:

- Servir de base para el proceso metodológico de la regulación

- Establecer los conceptos centrales que definen el Sistema Nacional de Contabilidad Pública (SNCP)

- Servir de guía al regulador para evaluar, permanentemente, las normas vigentes y para el desarrollo normativo sustancial y procedimental de la contabilidad pública

- Apoyar a los usuarios en la interpretación y aplicación de las normas

- Aportar en el proceso de construcción de la información contable por parte de quienes preparan y emiten la información 
- Apoyar a los evaluadores de la información en el proceso de realizar un juicio sobre la contabilidad pública, y servir de base para el desarrollo. (Contaduría General de la Nación, 2008, p. 6).

Los propósitos se refieren a los fines del SNCP y se expresan a partir del siguiente enunciado:

[...] el SNCP debe permitir el ejercicio del Control sobre los recursos y el patrimonio públicos, ser instrumento para la rendición de cuentas, viabilizar la gestión eficiente por parte de las entidades y generar condiciones de transparencia sobre el uso, gestión y conservación de los recursos y el patrimonio públicos. Estos propósitos son condicionantes del desarrollo conceptual e instrumental de la regulación contable pública (Contaduría General de la Nación, 2008, p. 6).

Los objetivos están relacionados con fines de la información contable pública, según las necesidades de los usuarios. Los objetivos de la información contable pública buscan hacer útiles los estados, informes y reportes contables considerados de manera individual, agregada y consolidada, provistos por el SNCP, satisfaciendo el conjunto de necesidades específicas y las demandas de los usuarios. Los objetivos de la información contable pública son: gestión pública, control público, divulgación y cultura. Estos han sido definidos luego de identificar y clasificar a los usuarios reales y potenciales.

La información contable debe observar características cualitativas que constituyen tributos inherentes al producto del SNCP, otorgándole la identidad y especificidad que permiten diferenciarla de información contable preparada con otros propósitos. Para garantizar la satisfacción de los objetivos de la información contable pública, ésta debe ser confiable, relevante y comprensible. Respecto a la ley 743, se toma como fundamento importante:

Artículo $\mathbf{7}^{\circ}$. Ley 743. Facultades. Para desarrollar las anteriores finalidades, las dependencias estatales de inspección, vigilancia y control tendrán las siguientes facultades: 
1. Revisar los libros contables, de actas y de afiliados de las organizaciones comunales.

2. Solicitar copia de los informes presentados a la asamblea.

3. Diseñar y aplicar instrumentos que permitan realizar revisiones periódicas al cumplimiento de la ley y los estatutos de las organizaciones.

4. Sancionar con suspensión o cancelación de la personería jurídica, según el caso, a las organizaciones comunales que estén incumpliendo la Ley 743 de 2002, sus decretos reglamentarios o sus estatutos.

Artículo 38. Ley 743. Funciones de la asamblea. Además de las funciones establecidas en los estatutos respectivos, corresponde a la asamblea general de los organismos de acción comunal:

- Determinar la cuantía de la ordenación de gastos y la naturaleza de los contratos que sean de competencia de la asamblea general, de la directiva, del representante legal, de los comités de trabajo empresariales y de los administradores o gerentes de las actividades de economía social;

- Adoptar y/o modificar los planes, programas y proyectos que los órganos de administración presenten a su consideración

- Aprobar en la primera reunión de cada año las cuentas y los estados de tesorería de las organizaciones;

- Aprobar o improbar los estados financieros, balances y cuentas que le presenten las directivas, el fiscal o quien maneje recursos de las organizaciones.

En el Artículo 56. Ley 743. Presupuesto. Menciona que todas las organizaciones comunales deben llevar contabilidad, igualmente elaborar presupuesto de ingresos y de gastos e inversiones para un período anual, el cual debe ser aprobado por la asamblea general y del que formará parte el presupuesto de las empresas de economía social que les pertenezcan. Sin embargo, la ordenación del gasto y la responsabilidad del sistema de contabilidad presupuestal recaen sobre los representantes legales de estas empresas. Y que de acuerdo a lo anterior se tienen en cuenta las facultades de las entidades que ejercen la vigilancia, inspección y control. Por último se hace énfasis en las finalidades del presupuesto, como son: 
- Planear los resultados de la organización en dinero y volúmenes.

- Controlar el manejo de ingresos y egresos de la empresa.

- Coordinar y relacionar las actividades de la organización.

- Lograr los resultados de las operaciones periódicas.

Y la importancia del presupuesto:

- Minimizar riesgos, servir de mecanismo para la revisión de políticas y estrategias de la empresa.

- Cuantificación en términos financieros los diversos componentes de su plan total de acción

- Permite mantener el plan de operaciones de la empresa en límites razonables.

\section{Objetivos del proyecto}

Objetivo general

Diseñar una propuesta para implementar un modelo de gestión financiera y contable en las JAC del municipio de Sogamoso.

\section{Objetivos específicos}

1). Elaborar un diagnóstico en el que se evidencie la forma en que se manejan los recursos financieros en las JAC.

2). Diseñar un módulo de manejo financiero y contable para ser aplicado en las JAC del municipio de Sogamoso. 


\section{Metodología}

Esta investigación es de tipo de exploratoria y responde a la siguiente pregunta: ¿Las JAC que manejan de forma transparente los recursos financieros pertenecen a comunidades más exitosas en su gestión y aceptación por parte de los entes públicos que deciden, de una u otra forma, apoyarlas con el desarrollo de proyectos que benefician a la población?

Actualmente no existe una legislación que obligue a las JAC a presentar de forma periódica informes de carácter financiero (por ejemplo: de ejecución presupuestal, tesorería, contable, estados de situación financiera y estado de resultados) ante entes de control como la Contraloría. Estos informes servirían para verificar el manejo contable y financiero de los recursos que administran los dignatarios electos por periodos de cuatro años, termino por el que son elegidas las JAC, los comités y sus delegados. En ese sentido, el impacto de este proyecto radica en capacitar y sensibilizar a los comunales para que manejen de forma adecuada los recursos que administran, teniendo comunidades más aptas, participativas y transparentes. La información para el diagnóstico situacional se recolectó a través de fuentes primarias: encuesta aplicada a los dignatarios de 82 juntas, y fuentes secundarias como la información suministrada por la Secretaria de Gobierno de Sogamoso.

\section{Población}

El municipio de Sogamoso está conformado por 134 JAC, de las cuales se piensa implementar la propuesta del módulo financiero y contable en el $45 \%$ de las juntas afiliadas a Asocomunal, que son Go juntas. 
Tabla 1. Cronograma

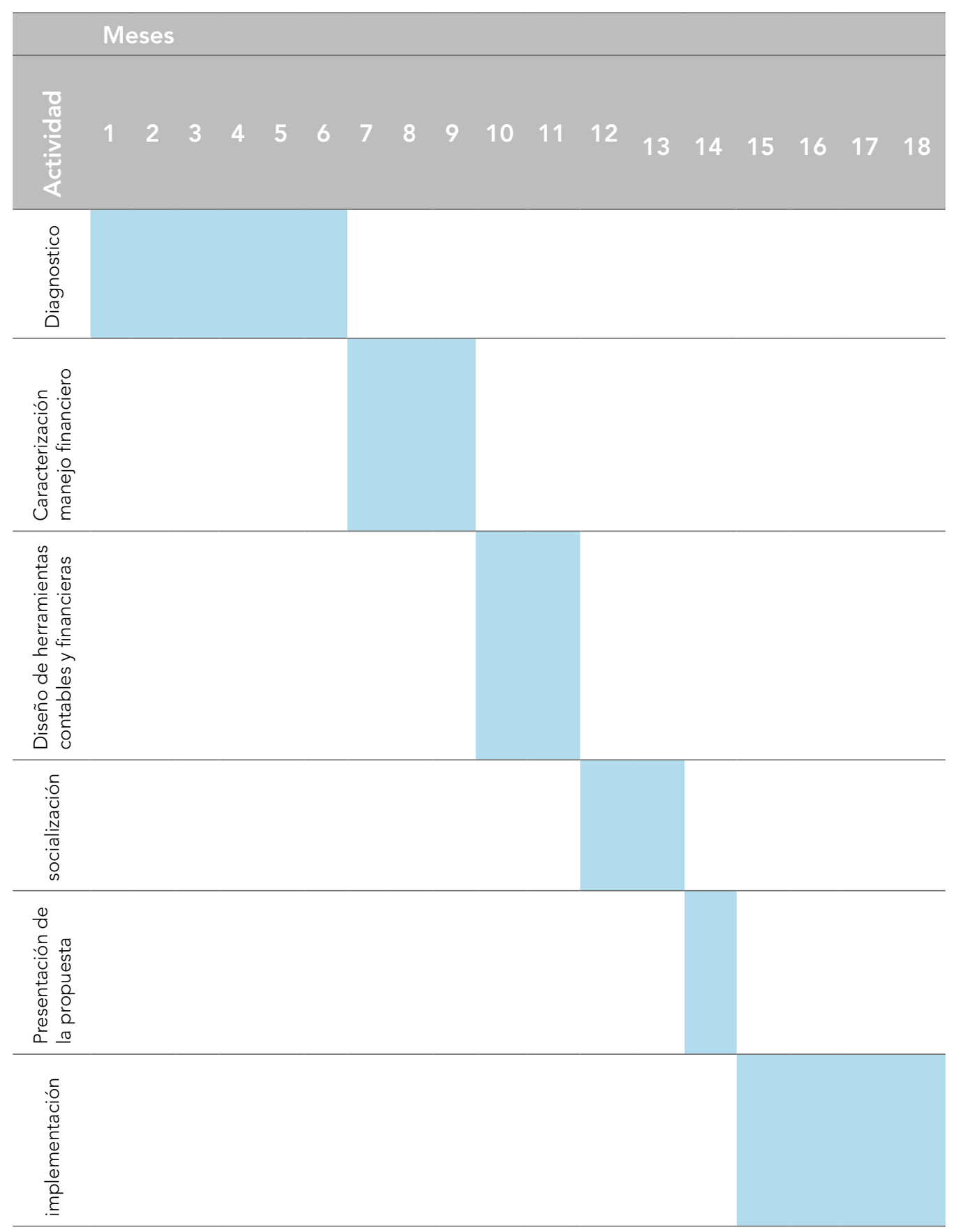

Fuente: elaboración propia 
Tabla 2. Presupuesto de costos

\begin{tabular}{|c|c|c|c|c|c|c|}
\hline $\begin{array}{l}\text { Costo talento } \\
\text { humano } \\
\text { Número de Horas } \\
\text { por fase de trabajo }\end{array}$ & 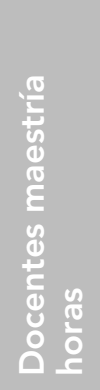 & 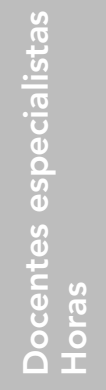 & 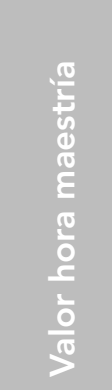 & 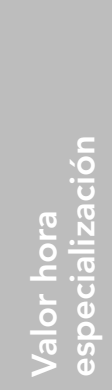 & 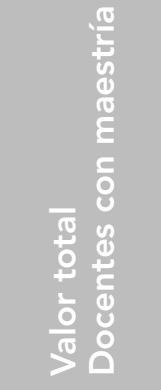 & 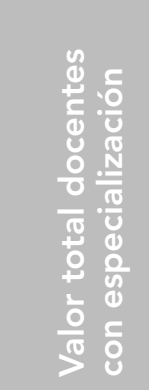 \\
\hline Horas seminario & 28 & 12 & 28.841 & 23.074 & 807.548 & 276.888 \\
\hline Horas diagnóstico & 50 & 50 & 28.841 & 23.074 & 1.4420 .50 & 1.153 .700 \\
\hline Horas sensibilización & 20 & 20 & 28.841 & 23.074 & 576.820 & 461.480 \\
\hline $\begin{array}{l}\text { Horas para elaboración de } \\
\text { cartilla sobre manejo contable y } \\
\text { financiero }\end{array}$ & 50 & 50 & 28.841 & 23.074 & 1.4420 .50 & 1.153 .700 \\
\hline Total horas maestría & 148 & & & & 4.268 .468 & \\
\hline Total horas especialista & & 132 & & & & 3.045 .768 \\
\hline total & 10.314 & 236 & & & & \\
\hline
\end{tabular}

Fuente: elaboración propia

\section{Resultados}

- Diseño del instrumento de recolección de información

- Tabulación y análisis de la información recolectada 


\section{Señor dignatario, ¿usted conoce cuáles y cuántos son los libros contables que deben manejar las JAC, de acuerdo a ley 743/2002?}

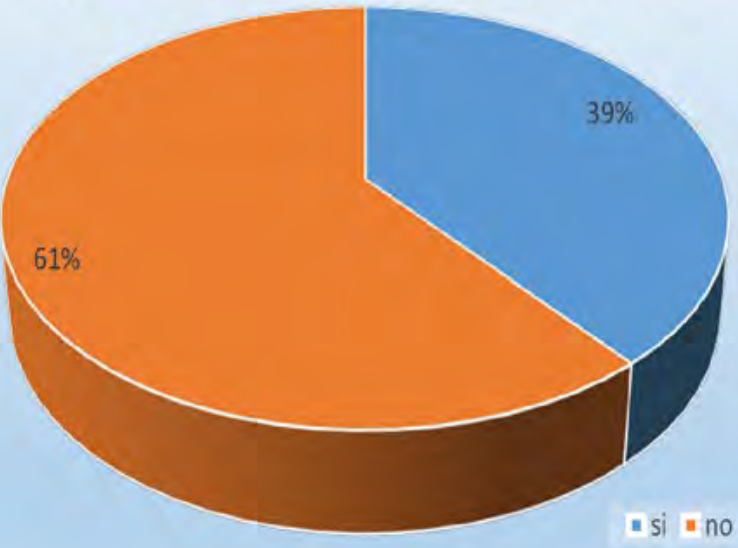

Figura 1. Conocimiento en libros contables

Fuente: elaboración propia

El 61\% de los dignatarios no conoce cuáles son los libros que deben manejar las JAC, mientras que el $39 \%$ indica que sí los conocen. Los libros que se deben llevar son: libro de inventarios, de caja, de afiliados, de actas de asamblea general y junta directiva, junto con los estados financieros.

¿Conoce el manejo de cada uno de los libros,

sus definiciones y el objeto para el cual fue creado?

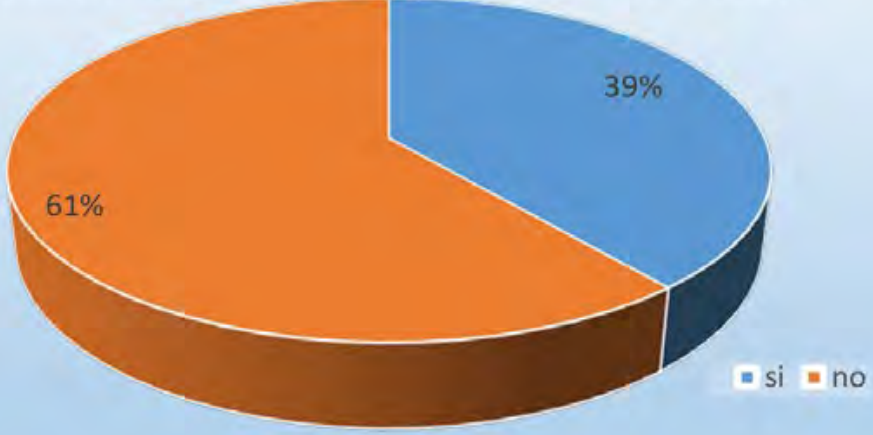

Figura 2. Conocimiento de los libros financieros

Fuente: elaboración propia 
El 61\% de los dignatarios no conoce el manejo de cada uno de los libros ni su objetivo y definición. El $39 \%$ de los dignatarios afirma conocer el manejo de cada uno de los libros con su definición y objetivo.

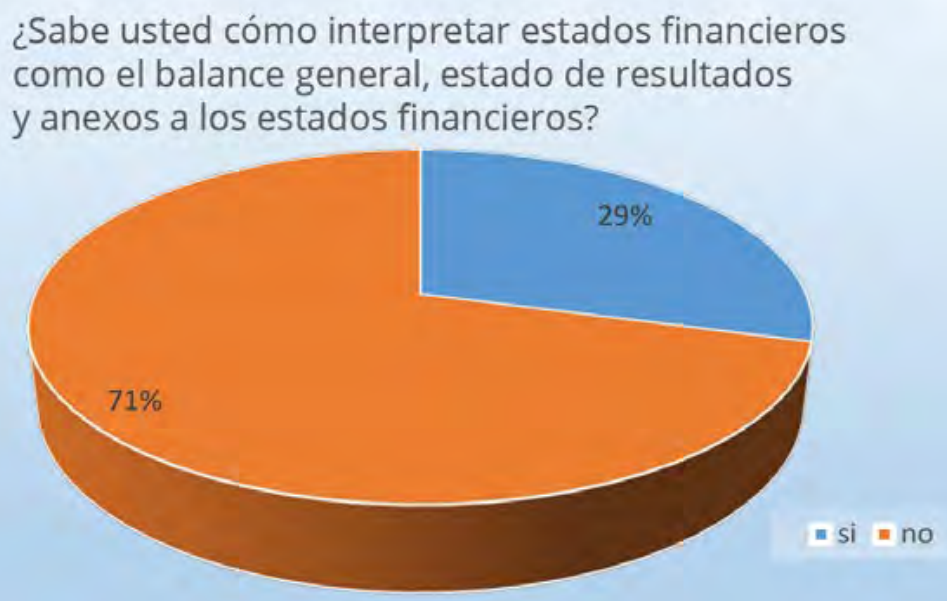

Figura 3. Conocimiento e interpretación de estados financieros

Fuente: elaboración propia

El $71 \%$ de los dignatarios no sabe cómo interpretar los estados financieros, mientras que el $29 \%$ sí sabe cómo interpretarlos.

¿Sabe cómo llevar de forma de acuerdo a la ley los libros de inventarios, caja, bancos y presupuesto?

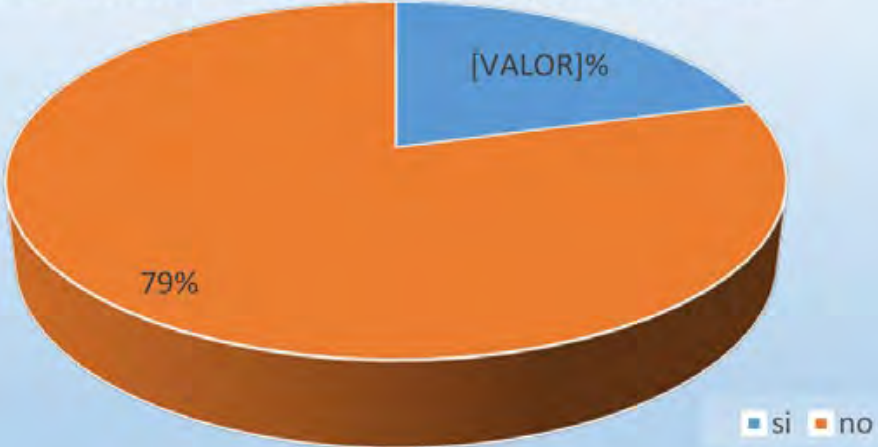

Figura 4. Conocimiento en libros de inventarios, caja, banco y presupuesto Fuente: elaboración propia 
El $79 \%$ de los dignatarios no saben cómo llevar de forma adecuada y de acuerdo a la ley los libros de inventarios, caja, bancos y presupuesto; mientras que el $17 \%$ sí lo sabe hacer.
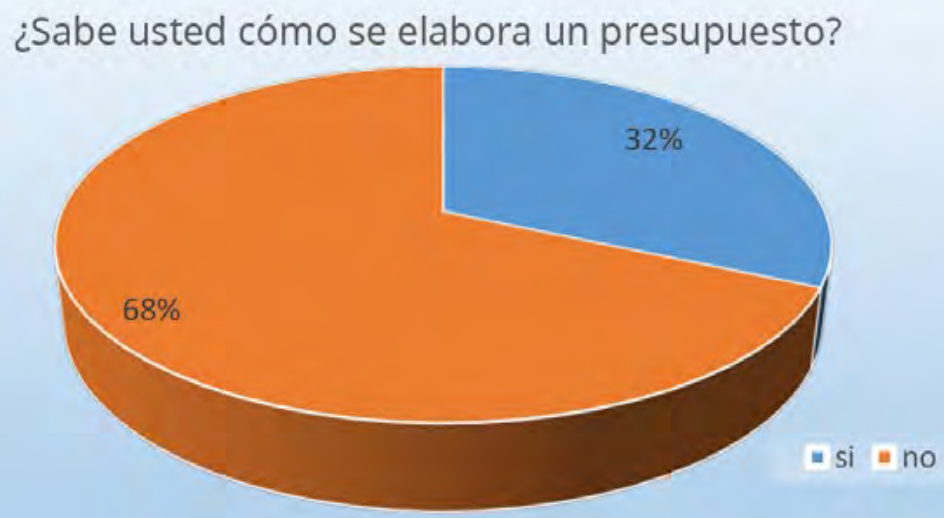

Figura 5. Elaboración de presupuesto

Fuente: elaboración propia

El $68 \%$ de los dignatarios no sabe cómo elaborar un presupuesto, mientras que el $32 \%$ sí lo sabe.

¿Sabe usted que informes deben presentar como junta Directiva ante la asamblea general?

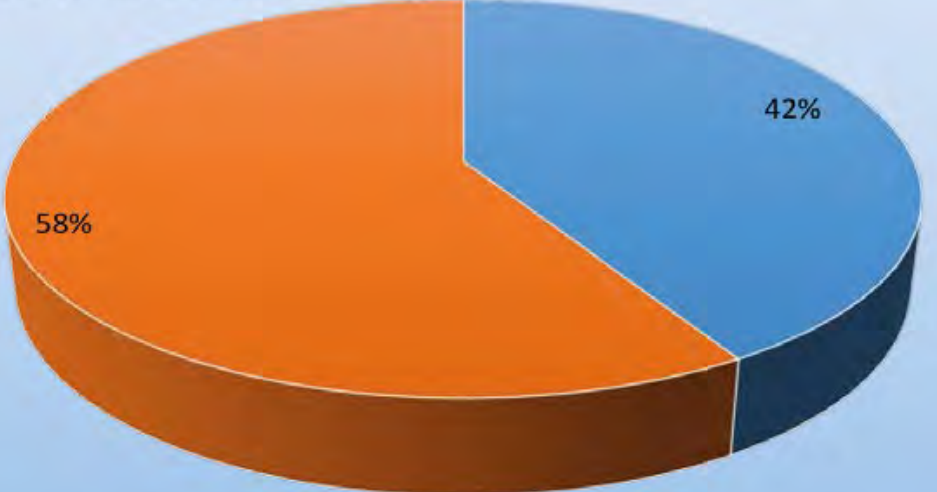

Figura 6. Informes para la Asamblea General

Fuente: elaboración propia 
El $58 \%$ de los dignatarios no sabe qué informes debe presentar como junta directiva ante la asamblea general, mientras el $42 \%$ si tiene conocimiento.

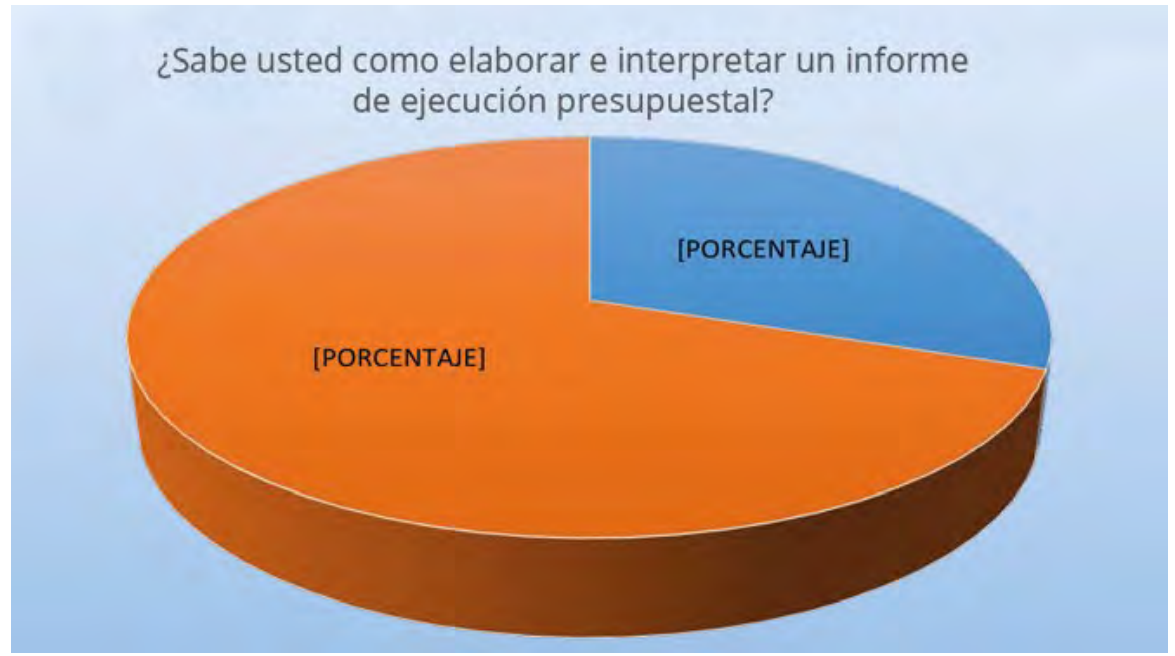

Figura 7. Elaboración e interpretación de la ejecución presupuestal

Fuente: elaboración propia

El $70 \%$ de los dignatarios no sabe cómo elaborar e interpretar un informe de ejecución presupuestal.

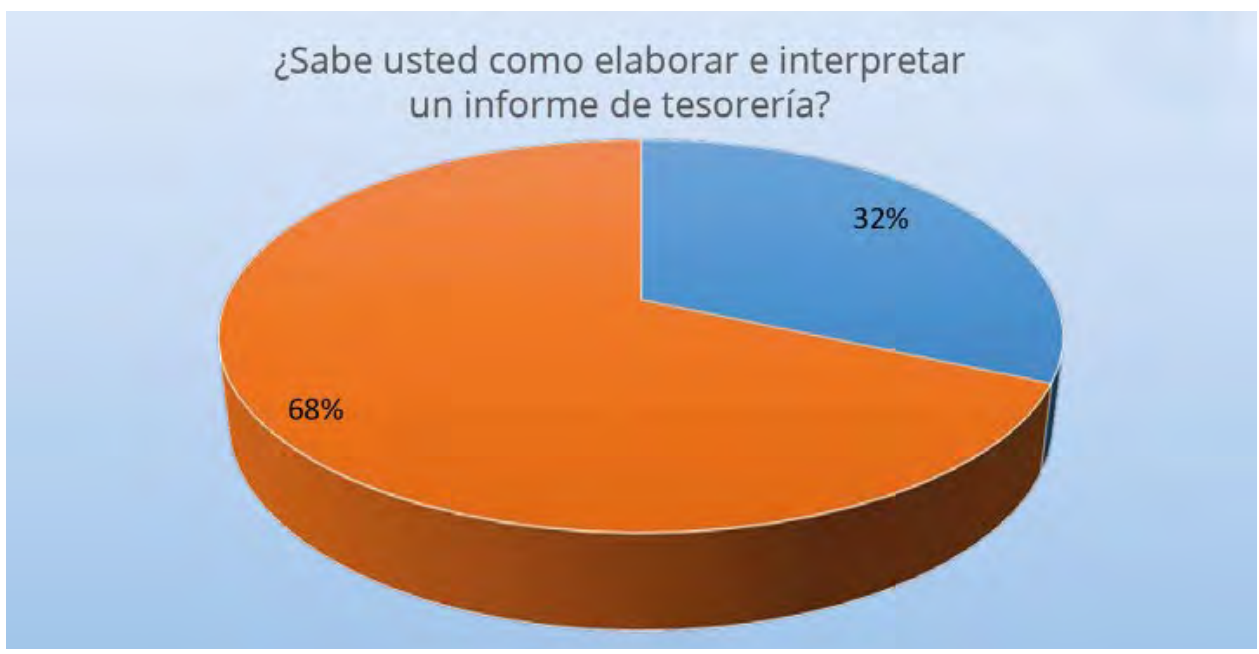

Figura 8. Elaboración e interpretación de informe de tesorería.

Fuente: elaboración propia 
El 68\% de los dignatarios no sabe cómo elaborar e interpretar un informe de tesorería, y el 32\% entiende cómo interpretar y elaborar u informe de tesorería.

\section{Actualmente, ¿cuentan con algún módulo educativo o cartilla que enseñe a manejar todo el sistema contable de las JAC?}

$1 \%$

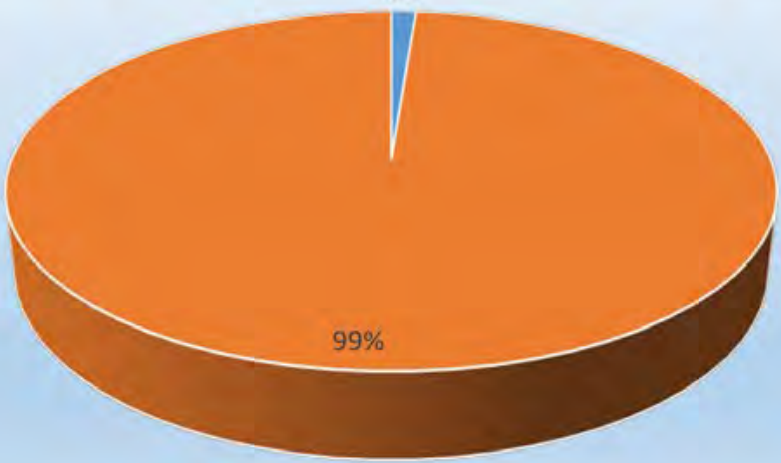

Figura 9. Guía contable

Fuente: elaboración propia

El $99 \%$ de los dignatarios no tiene un módulo educativo o cartilla guía para manejar el sistema contable de las juntas de acción comunal, solo el 1\% lo tiene.

¿Les gustaría ser beneficiarios de un proceso de capacitación gratuita en el que aprendan a manejar los libros contables y los informes financieros para ser presentados ante la asamblea y los organismos de control y vigilancia?

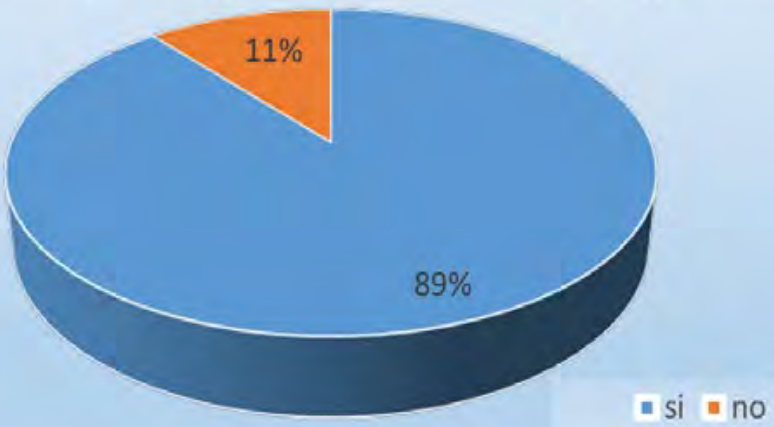

Fígura 10. Procesos de capacitación

Fuente: elaboración propia 
Al 89\% de los dignatarios les gustaría ser beneficiario de un proceso de capacitación gratuita con el fin de aprender a manejar los libros contables y los informes financieros para ser presentados ante la asamblea y los organismos de control y vigilancia.

Como Datos adicionales se tiene que el $95 \%$ de los dignatarios le gustaría tener una cartilla gratuita que les sirva como herramienta guía en el manejo del sistema contable y financiero de la JAC, solo al $5 \%$ no le gustaría. El $25 \%$ de los dignatarios estarían dispuestos a dedicar entre 1 y 2 horas mensuales para un proceso de capacitación en Manejo Contable y Financiero, el 32\% 1 hora semanal y el $43 \%$ entre 102 horas quincenales. El $89 \%$ de los dignatarios están dispuestos a trasladarse a la UNAD para beneficiarse de un proceso de capacitación en Manejo Contable y Financiero y el $11 \%$ no tiene la disposición para participar en un proceso de capacitación en Manejo Contable y Financiero.

El resultado del análisis nos indica el grado de conocimiento que actualmente tienen los dignatarios de las JAC en el manejo contable y financiero.

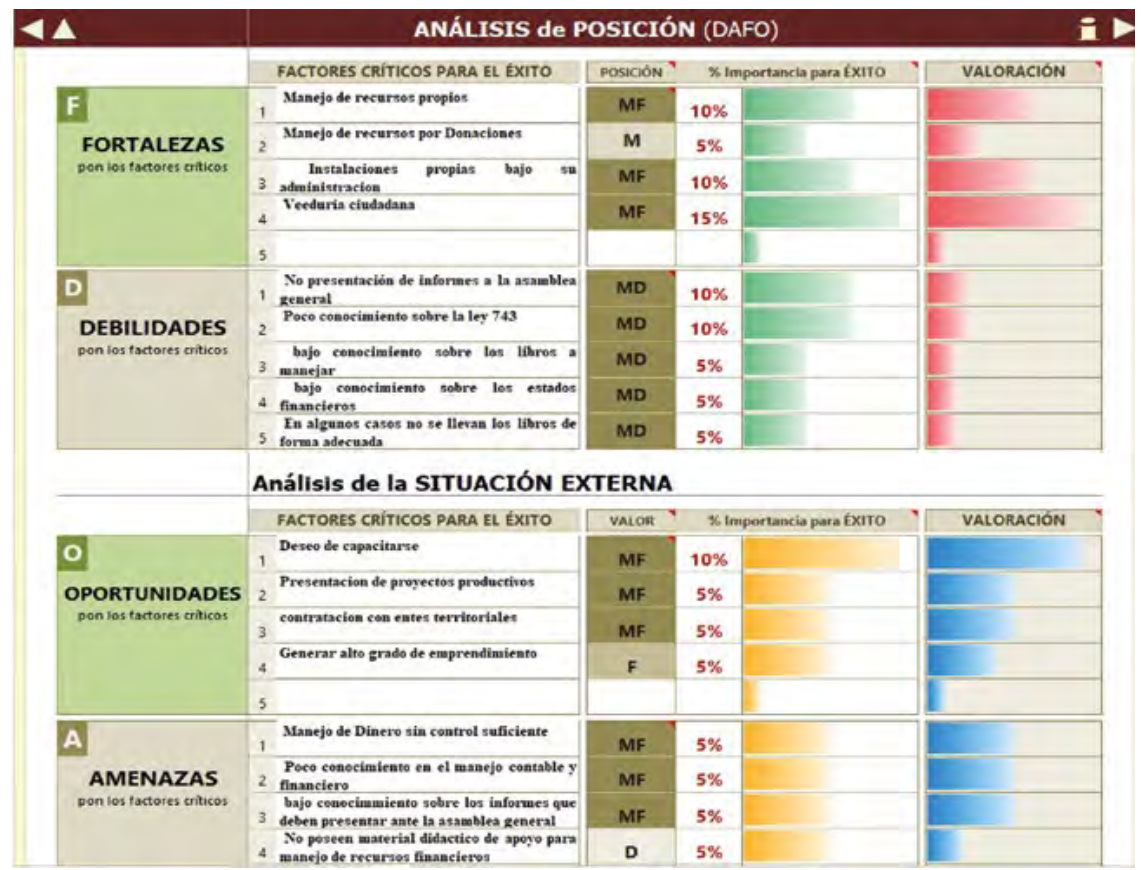

Figura 11. Factores externos e internos DOFA

Fuente: elaboración propia 


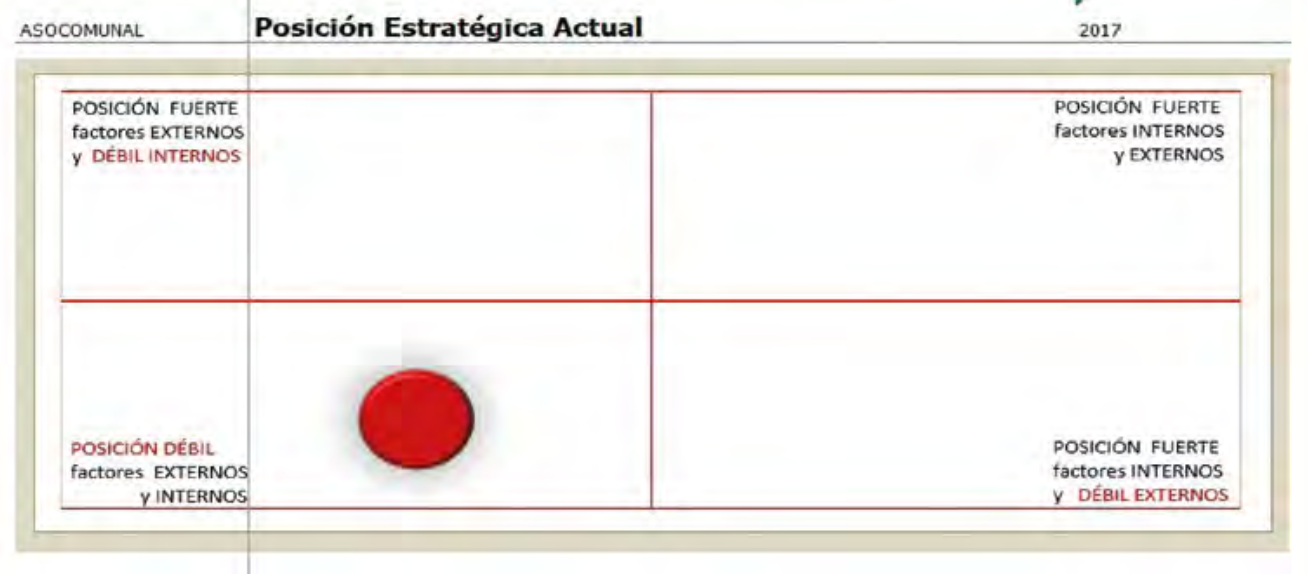

Figura 12. Posición estratégica Análisis del diagnostico

Fuente: elaboración propia

Del mismo modo, la figura 12 del plano cartesiano nos ubica en una posición débil en cuanto a los factores internos y externos, lo cual nos permite deducir que se debe dedicar tiempo en capacitación para fortalecer: la enseñanza en la presentación de informes ante la asamblea general; la socialización y aplicación de la ley 743; el manejo y conocimiento de los libros que se llevan en las JAC, junto con la interpretación básica de los estados financieros. Fortaleciendo estos aspectos se puede aprovechar el potencial que están obteniendo las JAC para manejar recursos propios, ya sea por autogestión, inversión, convenios o donaciones.

\section{Discusión o propuesta}

Elaboración del seminario taller sobre manejo contable y financiero

Está conformado por seis sesiones que se realizarán en las instalaciones de la universidad, y serán dirigidos por los investigadores del grupo Sol de Iraka de la escuela ECACEN. En este taller se abordarán los siguientes temas: 
Tabla 3. Cronograma seminario taller

\begin{tabular}{lll}
\hline Tema & Responsable & Fecha \\
\hline $\begin{array}{l}\text { Normatividad (Ley 743 y } \\
\text { decreto reglamentario) }\end{array}$ & Dr. Fabio Alonso Bonilla Gómez & 26 mayo \\
\hline Manejo de inventarios & Dra. Eva Inés Guatibonza Hernández & 09 de junio \\
\hline $\begin{array}{l}\text { Aspectos organizacionales } \\
\text { de las JAC }\end{array}$ & Dr. José Miguel Ángel Beltrán Gómez & 23 de junio \\
\hline $\begin{array}{l}\text { Aspectos básicos de } \\
\text { contratación }\end{array}$ & Dr. Armando Cáceres Quevedo & 7 de julio \\
\hline $\begin{array}{l}\text { Taller Contabilidad básica y } \\
\text { estados financieros básicos }\end{array}$ & Dr. Álvaro Bernal Rojas & 28 de julio \\
\hline $\begin{array}{l}\text { Presupuesto e informe de } \\
\text { tesorería }\end{array}$ & Dr. Aymer Román Barrera Novoa & 11 de agosto \\
\hline
\end{tabular}

Fuente: elaboración propia

\section{Registro fotográfico}

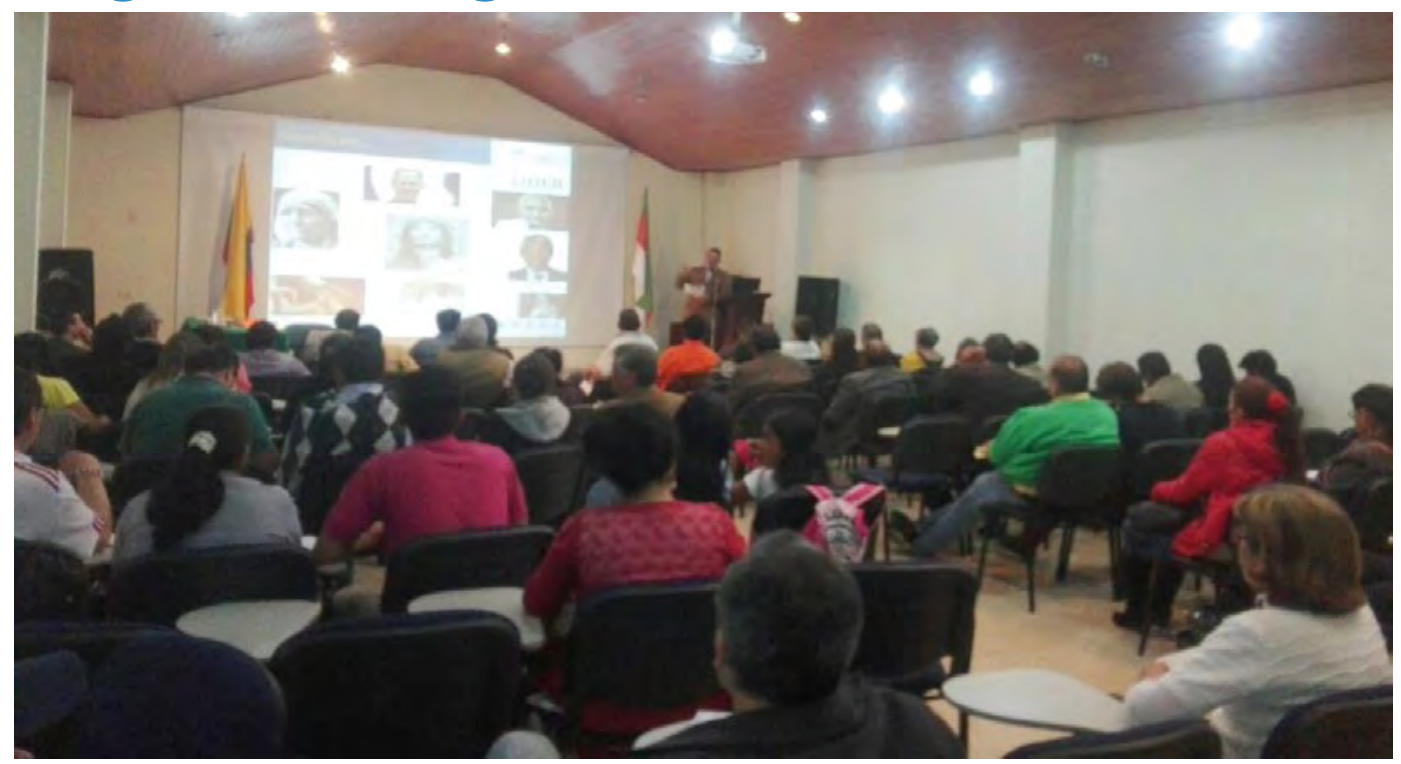

Figura 14: JAC Sogamoso

Fuente: elaboración propia 


\section{$\widehat{e}_{\text {PROSPECTA }}^{\text {COLONBA } 2017}$}

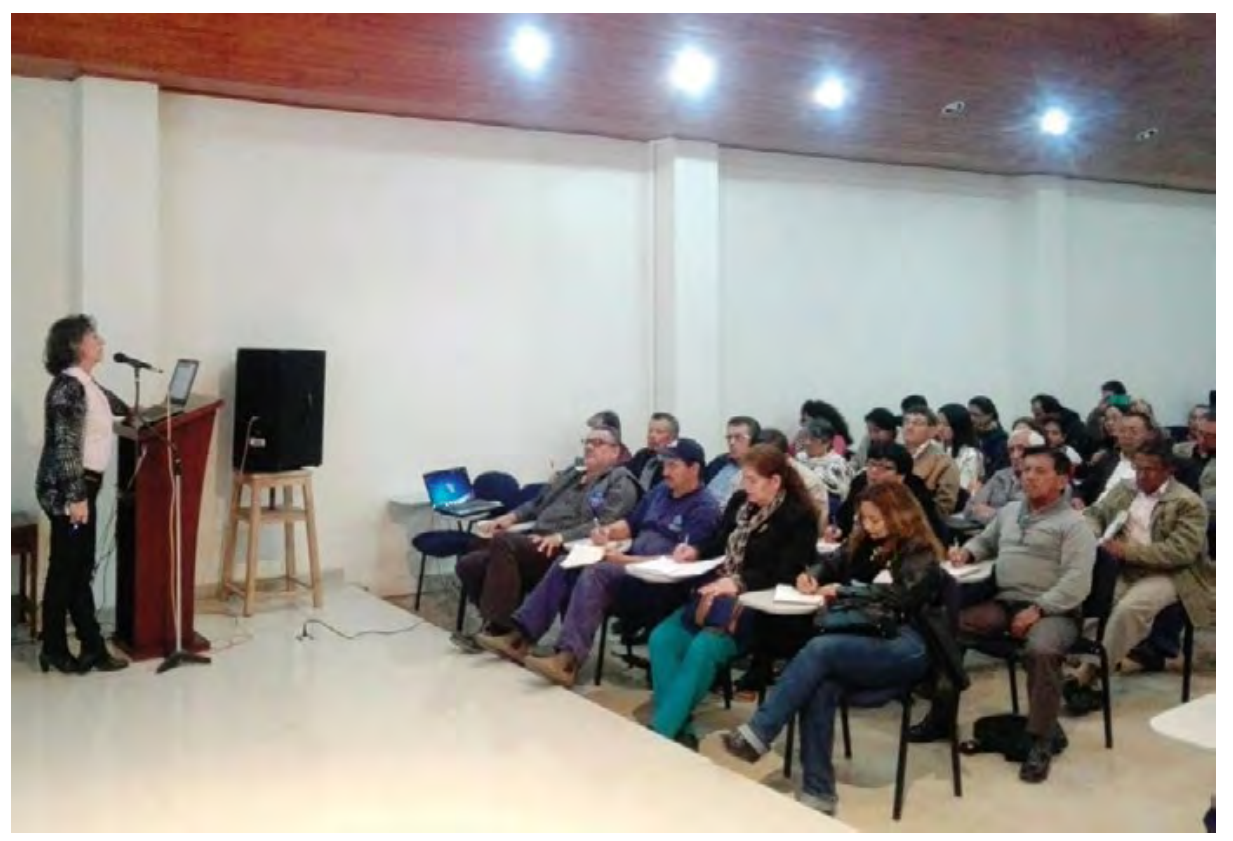

Figura 15. JAC Sogamoso

Fuente: elaboración propia

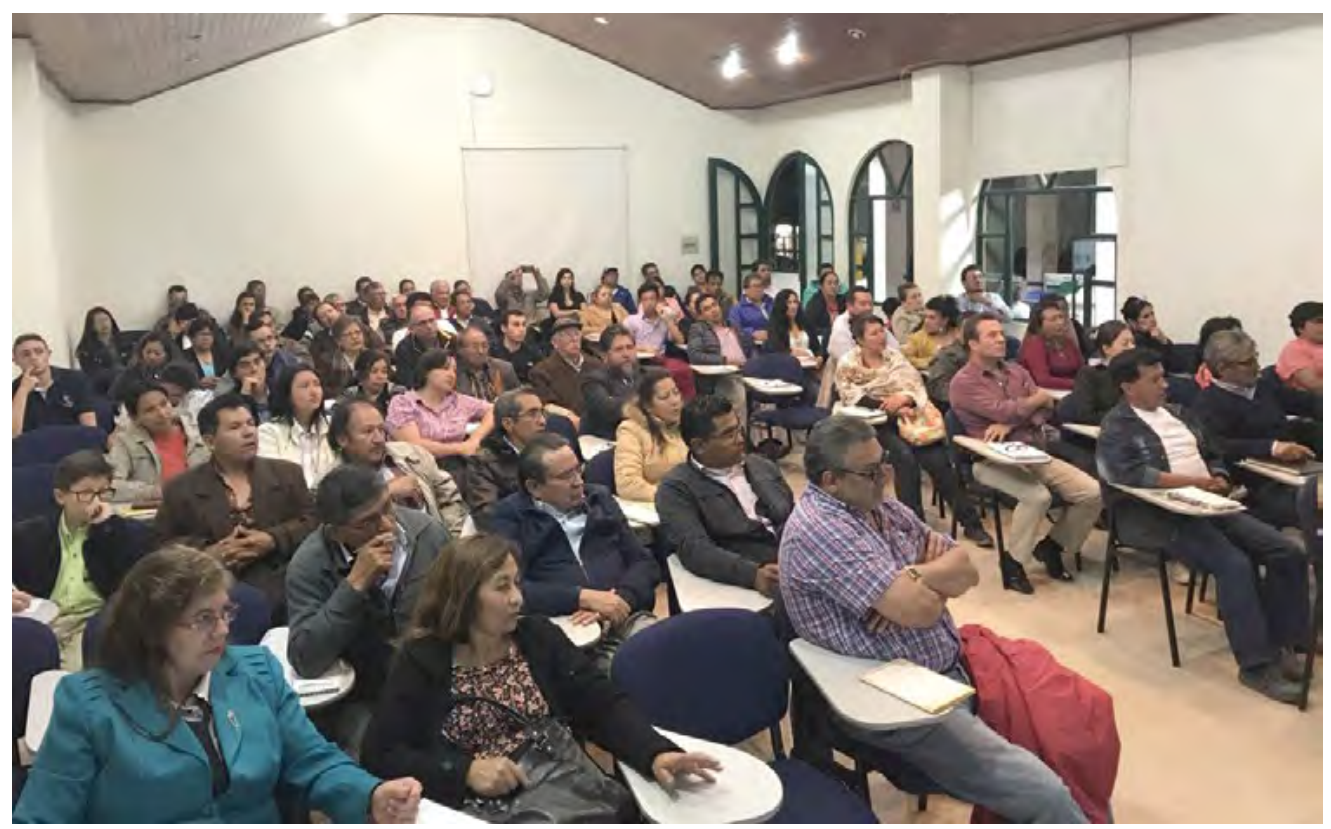

Figura 16. JAC Sogamoso

Fuente: elaboración propia 


\section{Propuesta para la elaboración de una cartilla sobre manejo contable y financiero en las JAC}

Se elaborará una cartilla que contiene los elementos básicos sobre el manejo contable y financiero, la cual podrá ser utilizada por todos los afiliados a las JAC. Además servirá de guía para despejar cualquier duda o inquietud generada por los dignatarios de la JAC durante el ejercicio de sus actividades. Algunos de los temas a tratar en la cartilla son: manejo de libros, conceptos básicos de contabilidad, normatividad general, manejo de inventarios y presupuestos básicos. A continuación se muestra una propuesta del diseño gráfico que podría tener la cartilla.

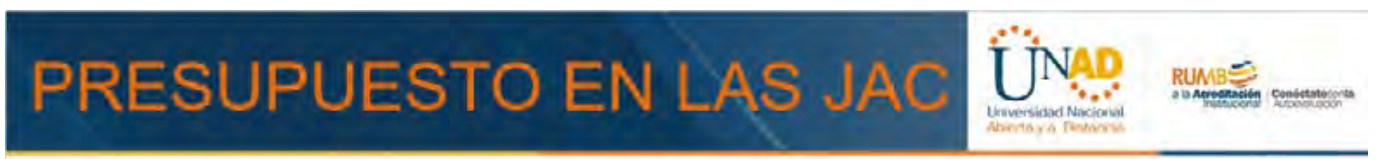

\section{Ejemplo}
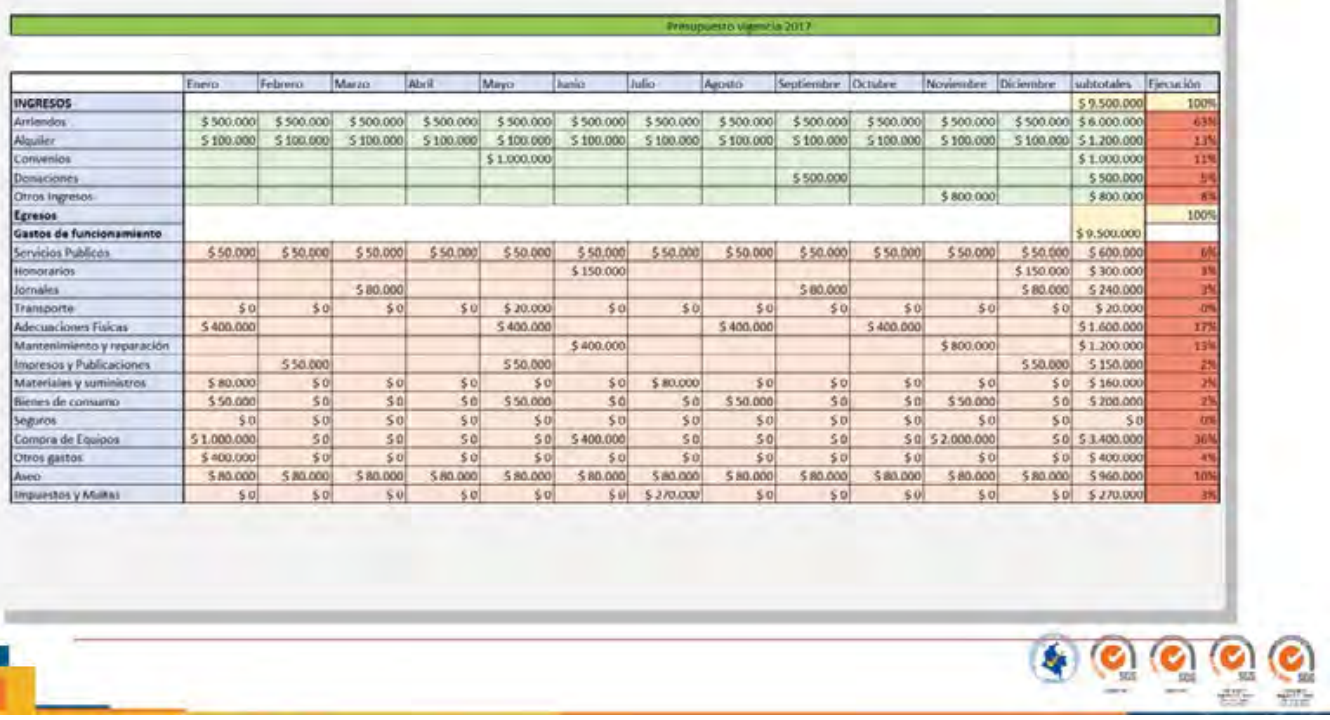

Figura 17. Propuesta cartilla

Fuente: elaboración propia 


\section{Conclusiones}

- A través del estudio se evidencia el grado de desconocimiento en el manejo contable y financiero que tienen los dignatarios de las JAC del municipio de Sogamoso, a la hora de optimizar la inversión de los recursos propios o aquellos derivados de la contratación pública.

- La Universidad Nacional Abierta y a Distancia, a través del proyecto de investigación liderado por el grupo Sol de Iraka, cumple con su misión de contribuir a la educación para todos mediante la proyección comunitaria, propiciando el desarrollo económico, social y humano sostenible de las comunidades regionales, locales y globales.

- A través del convenio con Asocomunal se ha logrado llegar a las JAC para lograr la cualificación de sus dignatarios en el manejo contable y financiero, de esta forma la comunidad participará con mayor tranquilidad para administrar los recursos financieros de una forma transparente y eficiente.

- Es importante la planeación, ejecución y control de los recursos financieros que se manejan en las JAC para lograr resultados positivos en gestión de convenios, recursos con la administración local, rendimiento y administración de los recursos propios. De esta manera se podrá lograr un beneficio común para todos los integrantes de una localidad.

\section{Referencias}

Alcarria, J. (2009). Contabilidad financiera I [en línea]. Disponible en http://bibliotecavirtual.unad.edu.co:2077/lib/unadsp/reader. action?ppg $=1 \&$ doc $\mid \mathrm{D}=11200925 \& \mathrm{tm}=1478272116136$

Alcarria, J. (2012). Introducción a la contabilidad [en línea]. Disponible en http://bibliotecavirtual.unad.edu.co:2077/lib/unadsp/reader. action?ppg $=1 \&$ docl $D=11201604 \& \mathrm{tm}=1478275425380$ 
Alcarria, J. (2009). Contabilidad financiera I. [en línea]. Disponible en http://bibliotecavirtual.unad.edu.co:2077/lib/unadsp/reader. action?ppg=1\&doclD=11200925\&tm=1478272116136

Contaduría General de la Nación. (2008). Régimen de contabilidad pública. Pag 8. [en línea]. Disponible en http://www.contaduria.gov. co/wps/wcm/connect/c5079258-7216-48e8-aecf-d116f0df2c59/ Plan+General+de+Contablidad+versi\%C3\%B3n+2007.2+\%28PGCP\%29. pdf?MOD=AJPERES\&CACHEID=c5079258-7216-48e8-aecf-d116f0df2c59

Constitución Política de Colombia. (1991). Titulo 1. De los principios fundamentales. Articulo 2. [en línea]. Disponible en http://www.constitucioncolombia.com/titulo-1

Rincón, S. (2011). Guía de costos para micro y pequeños empresarios: una manera fácil y sencilla de crecer [en línea]. Bogotá, D.C., Colombia: Ecoe Ediciones. Disponible en http://bibliotecavirtual.unad.edu.co:2077/lib/unadsp/reader. action?ppg $=26 \&$ doc $\mid \mathrm{D}=10552379 \& \mathrm{tm}=1480710652346$

\section{Anexo 1}
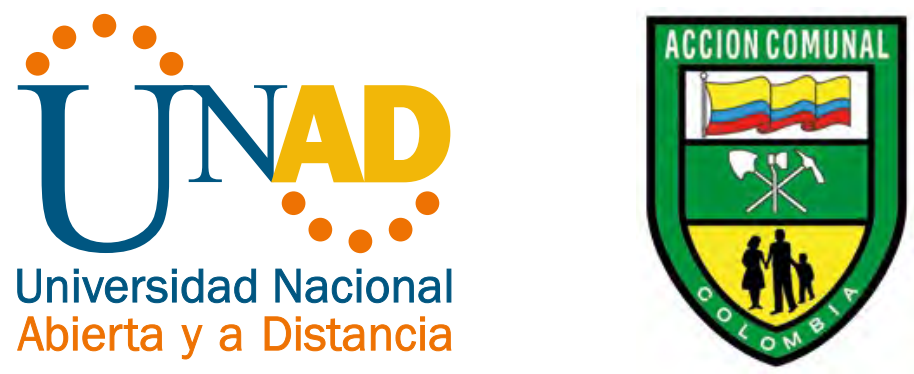

\section{ENCUESTA SOBRE CONOCIMIENTO BĀSICO FINANCIERO EN LAS JUNTAS DE ACCIŌN COMUNAL AFILIADAS A ASOCOMUNAL SOGAMOSO}

Estimado dignatario de las Junta de Acción Comunal, este es un instrumento de recolección de información para la elaboración de un diagnóstico situacional 
que ayudará a determinar el grado de conocimiento de nuestros comunales en torno al manejo del sistema contable en las juntas de acción comunal.

Agradecemos su valiosa colaboración para el diligenciamiento de esta encuesta.

1). ¿Conoce usted cuáles y cuántos son los libros contables que deben manejar las juntas de acción comunal, de acuerdo con la Ley 743/2002?

Sí

No

2). ¿Conoce el manejo de cada uno de los libros, incluyendo la definición y objetivo para el cual fue creado?

Sí

No

3). ¿Sabe usted cómo interpretar estados financieros como el balance general, estado de resultados, anexos a los estados financieros?

Sí

No

4). ¿Sabe cómo llevar de forma adecuada y de acuerdo a la ley los libros de inventarios, caja, bancos y presupuesto?

Sí___ No ___

5). ¿Sabe usted cómo se elabora un presupuesto?

Sí

No

6). ¿Sabe usted qué informes debe presentar como junta directiva ante la asamblea general?

Sí

No

7). ¿Sabe usted cómo elaborar e interpretar un informe de ejecución presupuestal?

Sí

No 
8). ¿Sabe usted cómo elaborar e interpretar un informe de tesorería?

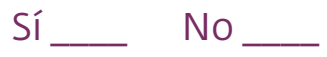

9). ¿Actualmente poseen algún módulo educativo o cartilla que enseñe a manejar la información contable de las juntas de acción comunal?

Sí

Sín_ No __

10). LLe gustaría ser beneficiario de un proceso de capacitación gratuita para aprender a manejar los libros contables y los informes financieros que deben presentarse ante la asamblea y los organismos de control y vigilancia?

Sí

No

11). ¿Le gustaría tener una cartilla gratuita que le sirva como herramienta para aprender y llevar el sistema contable de las juntas de acción comunal?

Sí

No

12). ¿Cuánto tiempo estaría dispuesto a dedicar a un proceso de capacitación contable para la juntas de acción comunal?

a). Entre 1 y 2 horas quincenales

b). Entre 1 y 2 horas mensuales

c). 1 hora a la semana

13). ¿Estaría usted dispuesto a trasladarse a la UNAD - Sogamoso para beneficiarse del proceso de capacitación?

Sí

No

Agradecemos su buena disposición y valiosa colaboración.

Grupo de Investigación Sol de Iraka - ECACEN - UNAD - Sogamoso 